\title{
Structural changes in metastable austenitic steel during equal channel angular pressing and subsequent cyclic deformation
}

\author{
S.V. Dobatkin ${ }^{\mathrm{a}, \mathrm{b}}$, W. Skrotzki ${ }^{\mathrm{c}}$, O.V. Rybalchenko ${ }^{\mathrm{a}, \mathrm{b}, *}$, V.F. Terent'ev ${ }^{\mathrm{a}}$, A.N. Belyakov ${ }^{\mathrm{d}}$, \\ D.V. Prosvirnin ${ }^{\mathrm{a}}$, G.I. Raab ${ }^{\mathrm{e}}$, E.V. Zolotarev ${ }^{\mathrm{b}}$ \\ ${ }^{a}$ A. A. Baikov Institute of Metallurgy and Materials Science of RAS, Leninsky prospect, 49, 119334 Moscow, Russia \\ b National University of Science and Technology "MISIS", Laboratory of Hybrid Nanostructured Materials, Leninsky prospect, 4, 119991 Moscow, Russia \\ ${ }^{\mathrm{c}}$ Technische Universität Dresden, Institute of Solid State and Materials Physics, Haeckelstrasse 3, D-01062 Dresden, Germany \\ d Belgorod State University, Pobeda st., 85, 308015 Belgorod, Russia \\ e Ufa State Aviation Technical University, Institute of Physics of Advanced Materials, K. Marx Street 12, 450000 Ufa, Russia
}

\section{A R T I C L E I N F O}

\section{Keywords:}

Stainless steel

Equal channel angular pressing

Ultra-fine grained structure

Deformation-induced martensite

Twinning

Mechanical and fatigue properties

\begin{abstract}
A B S T R A C T
The paper reports a substantial improvement of the static and cyclic strength of a Cr-Ni-Ti austenitic stainless steel nanostructured by equal channel angular pressing (ECAP). After ECAP at room temperature or $673 \mathrm{~K}$, the mean grain size decreased from $14 \mu \mathrm{m}$ to $430 \mathrm{~nm}$ or $940 \mathrm{~nm}$, respectively; corresponding ultimate tensile strength increased from $610 \mathrm{MPa}$ to $1230 \mathrm{MPa}$ or $940 \mathrm{MPa}$, and the fatigue limit increased from $275 \mathrm{MPa}$ to $375 \mathrm{MPa}$ or $475 \mathrm{MPa}$. These enhanced strength properties result from the grain refinement assisted by the intensive twinning in the austenite during ECAP at room temperature and $673 \mathrm{~K}$ as well as partial martensitic transformation during ECAP at room temperature. Moreover, the partial martensitic transformation and an increase in the fraction of high angle grain boundaries during subsequent high-cycle fatigue tests were particularly favorable for the improvement of fatigue properties.
\end{abstract}

\section{Introduction}

Austenitic stainless steels have found wide applications in nuclear, petrochemical, and other industries due to their great combination of high strength and good corrosion resistance. Moreover, metastable austenitic stainless steels have the possibility of adjusting properties due to phase transformations [1-7]. It should be noted that one of the key properties for the practical use of stainless steels is their good fatigue strength. Furthermore, it is important to emphasize that the grain size is a major structural parameter that strongly affects the mechanical properties of metals. The microstructure of metallic materials may be substantially refined to ultrafine grained (UFG) or even to nanograined state by severe plastic deformation (SPD) via equal channel angular pressing (ECAP). ECAP involves extremely large imposed plastic strains without a significant change of the dimensions of the billet. A significant refinement of the structural elements in stainless steels by ECAP leads to an increase of their strength and improvement of the fatigue properties $[1,5,6,8-11]$.

So far a large number of works have been focused on the study of the fatigue strength of UFG nonferrous metals and alloys [12-17]. A decrease in the grain size increases the yield stress and the ultimate tensile strength, and also improves the fatigue strength, especially of materials with low stacking fault energy, making crack nucleation difficult $[18,19]$. On the other hand, a small grain size may have a negative effect on the fatigue crack growth resistance, as cracks can propagate along the grain boundaries [20].

Despite a large amount of papers reporting on the fatigue strength of UFG materials, only a limited number of publications discuss the fatigue behavior of UFG austenitic stainless steels. Hamada et al. [21] have shown that the fatigue limit of a UFG 301LN stainless steel and a TWIP steel with a high Mn content exceeds $630 \mathrm{MPa}$ and $560 \mathrm{MPa}$, respectively. Their high-cycle fatigue strength is considerably higher than that of their coarse-grained counterpart (350 MPa and $400 \mathrm{MPa}$, respectively). Ueno et al. [9] successfully obtained a bulk nanocrystalline grain structure in a low carbon $316 \mathrm{~L}$ stainless steel by means of ECAP at $423 \mathrm{~K}$. They observed a substantial increase of the fatigue limit with values of $570 \mathrm{MPa}$ after $3 \mathrm{ECAP}$-passes. Furthermore, it is interesting to note that in this study the ratio of fatigue limit to ultimate tensile strength after ECAP is greater than for coarse grain stainless steel, which indicates the best working capacity of the material under cyclic loading $\mathrm{Cr}-\mathrm{Ni}-\mathrm{Ti}$ austenitic stainless steels are meta-stable at room temperature [22-25]. The strain-induced martensitic

\footnotetext{
* Corresponding author at: A. A. Baikov Institute of Metallurgy and Materials Science of RAS, Leninsky prospect, 49, 119334 Moscow, Russia.

E-mail address: rybalch@mail.ru (O.V. Rybalchenko).
} 
Table 1

Chemical composition of the Cr-Ni-Ti stainless steel.

\begin{tabular}{llllllllll}
\hline Elements & $\mathrm{C}$ & $\mathrm{Cr}$ & $\mathrm{Ni}$ & $\mathrm{Cu}$ & $\mathrm{Ti}$ & $\mathrm{Si}$ & $\mathrm{Mn}$ & $\mathrm{S}, \mathrm{P}$ & $\mathrm{Fe}$ \\
\hline Amount (wt\%) & 0.07 & 17.3 & 9.2 & 0.2 & 0.7 & 0.6 & 1.4 & 0.003 & balance \\
\hline
\end{tabular}

transformation may result in so-called transformation-induced plasticity (TRIP) effect and remarkably alter the deformation behavior of the austenitic stainless steels [23-25]. The TRIP effect promotes the strain hardening leading to simultaneous increase in the strength and ductility [23]. Also, the development of strain-induced martensite is accompanied by an increase in the flow stress during low cycle fatigue tests [26]. Significant increase in the yield strength and the ultimate tensile strength has been achieved by the development of UFG microstructure in meta-stable austenitic steels [27-30]. The beneficial effect of grain refinement on the mechanical properties of meta-stable austenite was attributed to the austenite stabilization and the promotion of Luders band deformation associated with strain-induced martensitic transformation [24,27].

Nonetheless, the reason for the increase of fatigue strength of UFG stainless steels is still unclear. Moreover, the structural and phase transformations in metastable austenitic steels during high-cycle fatigue tests have not been investigated properly. Therefore, an important goal of this work is to evaluate the effect of structural and phase transformations of a metastable austenitic stainless steel during ECAP on the mechanical properties upon subsequent static and cyclic loading.

\section{Experimental procedure}

The chemical composition of the stainless $\mathrm{Cr}-\mathrm{Ni}$-Ti steel is shown in Table 1. The material in as-received condition was austenitized at $1323 \mathrm{~K}$ for $1 \mathrm{~h}$ and water quenched. ECAP was carried out via route $\mathrm{Bc}$ on billets of $20 \mathrm{~mm}$ in diameter and $80 \mathrm{~mm}$ long using a die with channels intersecting at $120^{\circ}$ and a graphite lubricant [31]. The samples were processed by four ECAP-passes at room temperature (RT) and by six ECAP-passes at $673 \mathrm{~K}$. The true strain applied to the billet per pass for the defined die geometry equals 0.9 (shear strain $\gamma=1.5$ ) $[32,33]$.

The tensile and fatigue specimens with a gage length of $15 \mathrm{~mm}$ and a cross-section of $1.5 \mathrm{~mm} \times 7 \mathrm{~mm}$ were cut by a wire spark cutter from the ECAP billets. The specimens were mechanically polished using SiC grit papers and diamond paste and then electrolytically polished at RT under a voltage of $15 \mathrm{~V}$ for $5 \mathrm{~min}$ in a solution containing $100 \mathrm{~g}$ chromic anhydride and $850 \mathrm{ml}$ orthophosphoric acid.

The tensile tests were performed using an INSTRON 3380 machine with a load capacity of $100 \mathrm{kN}$. The high-cycle fatigue tests were carried out under repeated tension conditions in an INSTRON 8801 servo-hydraulic machine with a load capacity of $100 \mathrm{kN}$ operated at $40 \mathrm{~Hz}$ testing frequency and a stress ratio of $\mathrm{R}=0.1$.

The microstructure was investigated using an Olympus PME 3 optical microscope and a JEM-2100 transmission electron microscope operated at $200 \mathrm{kV}$. The samples for the metallographic analysis were electrolytically etched in aquafortis at RT and $3 \mathrm{~V}$. Thin foils for transmission electron microscopy (TEM) were mechanically ground to $90 \mu \mathrm{m}$ and thinned to perforation by twinjet electrolytic polisher with a solution of $10 \% \mathrm{HClO}_{4}$ in $\mathrm{CH}_{3} \mathrm{COOH}$ at $25 \mathrm{~V}$. X-ray diffraction (XRD) was carried out with a DRON 4.07 diffractometer. Electron backscatter diffraction (EBSD) mapping was performed with a Carl Zeiss Ultra 55 scanning electron microscope equipped with a CCD camera. The Channel 5 software was used to analyze the EBSD data.

\section{Results and discussion}

\subsection{The microstructure of austenitic steel in the initial state}

The microstructure of the metastable $\mathrm{Cr}-\mathrm{Ni}$-Ti steel after quenching is shown in Fig. 1. A typical coarse grained austenitic microstructure with an average grain size of about $25 \mu \mathrm{m}$ and the annealing twins are clearly seen in Fig. 1b and c.

EBSD was used to determine the misorientation between adjacent structural elements and their frequency distribution. The average sizes of structural elements with high-angle $\left(\geq 15^{\circ}\right)$ and low-angle $\left(\leq 15^{\circ}\right)$ boundaries are nearly the same (Table 2 ). This means that the fractions of low angle grain boundaries is small (15\%) and the subgrain and grain sizes are approximately the same. Taking into account annealing twins with their special $\Sigma 3$ boundaries, the average grain size comprises about $14 \mu \mathrm{m}$. It supports the aforesaid and the existence of many twins in the microstructure. In the present case, $85 \%$ are high-angle grain

Table 2

Microstructural characteristics of metastable austenitic steel according to EBSD and XRD analysis.

\begin{tabular}{|c|c|c|c|c|c|c|c|}
\hline \multirow[t]{2}{*}{ Processing } & & & \multirow[t]{2}{*}{ Quenching } & \multicolumn{2}{|c|}{ ECAP at RT } & \multicolumn{2}{|c|}{ ECAP at $673 \mathrm{~K}$} \\
\hline & & & & & $\begin{array}{l}\text { Cyclic } \\
\text { testing }^{\mathrm{a}}\end{array}$ & & $\begin{array}{l}\text { Cyclic } \\
\text { testing }\end{array}$ \\
\hline \multirow{4}{*}{$\begin{array}{c}\text { Average size, } \\
{[\mu \mathrm{m}]}\end{array}$} & SE & & 13.2 & 0.36 & 0.36 & 0.5 & 0.46 \\
\hline & $\left(>2^{\circ}\right)^{\prime \prime}$ & $\begin{array}{l}\text { without } \\
\text { twins }\end{array}$ & 23 & 0.37 & 0.37 & 0.5 & 0.47 \\
\hline & Grains & & 13.7 & 0.41 & 0.44 & 0.94 & 0.63 \\
\hline & $\left(>15^{\circ}\right)^{*}$ & $\begin{array}{l}\text { without } \\
\text { twins }\end{array}$ & 25.4 & 0.43 & 0.45 & 0.94 & 0.64 \\
\hline \multirow[t]{3}{*}{ Fraction, [\%] } & $\Sigma 3$ & & 50 & 2.6 & 1 & 0.3 & 0.6 \\
\hline & LAGBs" & & 15 & 41 & 35 & 46 & 30 \\
\hline & HAGBs" & & 85 & 59 & 65 & 54 & 70 \\
\hline \multirow{2}{*}{$\begin{array}{c}\text { bcc - phase, } \\
\text { [vol\%] }\end{array}$} & by XRD & & 5.2 & 38.3 & 43.8 & 0 & 10.3 \\
\hline & by EBSD & & 23 & 36 & 50 & 0.3 & 13.8 \\
\hline
\end{tabular}

* misorientation, SE - structural element, LAGBs - low-angle grain boundaries, HAGBs - high-angle grain boundaries.

${ }^{\mathrm{a}} \sigma_{\max }=600 \mathrm{MPa}, \mathrm{N}=7 \times 10^{4}$ after ECAP at RT.

b $\sigma_{\max }=600 \mathrm{MPa}, \mathrm{N}=1.9 \times 10^{5}$ after ECAP at $673 \mathrm{~K}$.

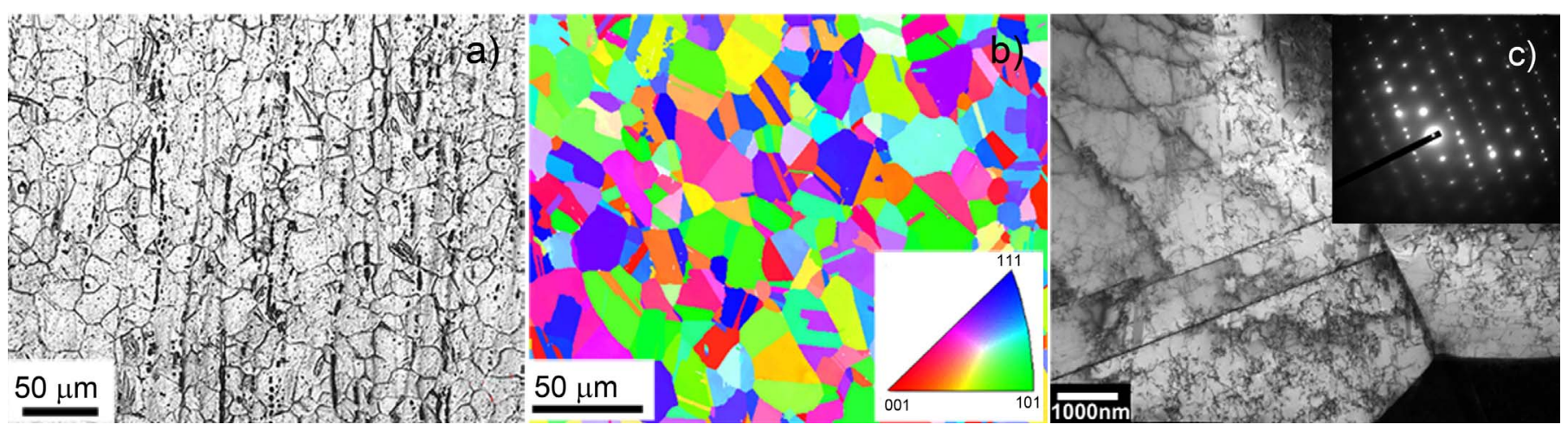

Fig. 1. The microstructure (a), orientation map (b) and TEM image (c) of Cr-Ni-Ti steel in the as quenched condition. 

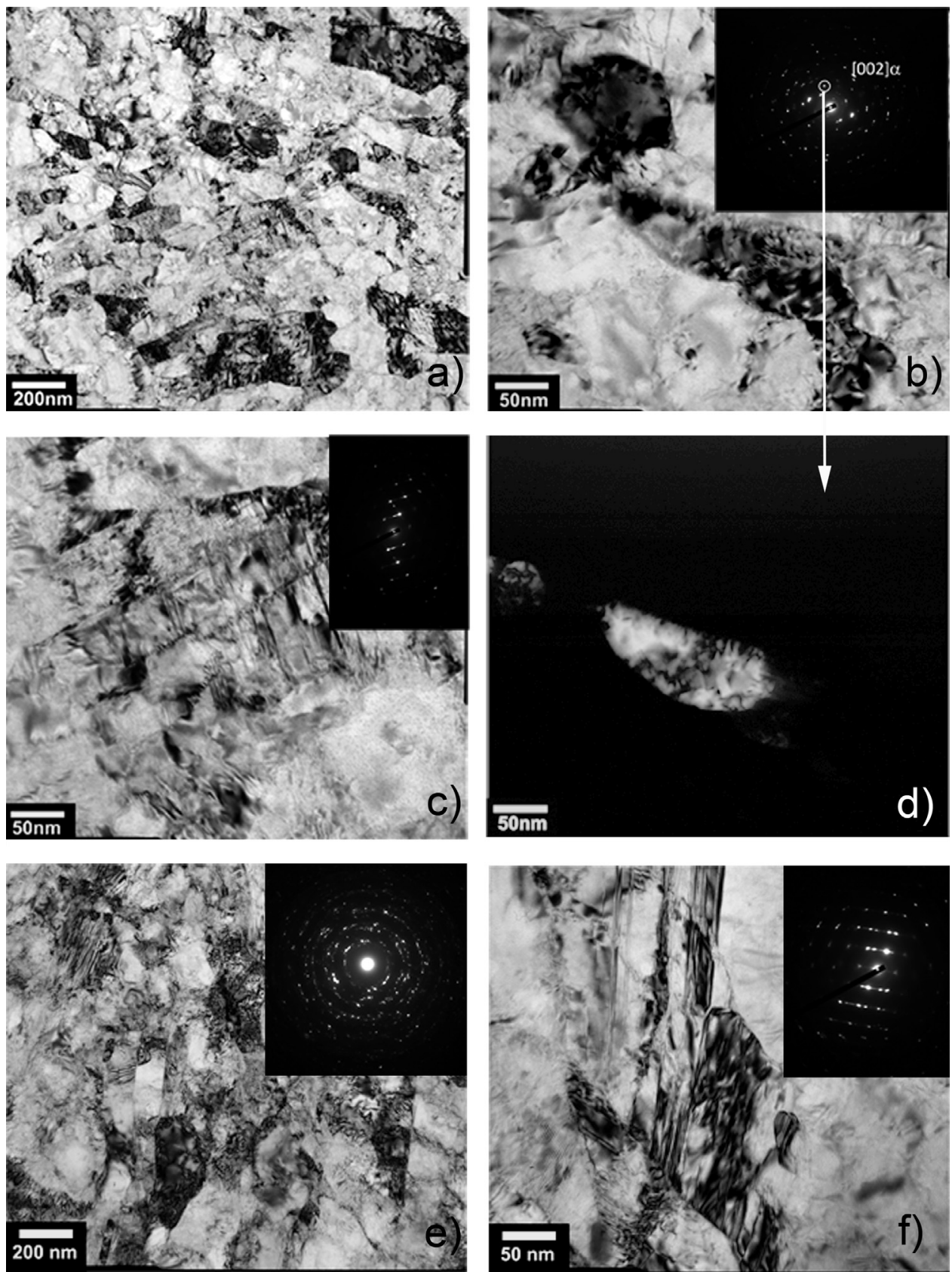

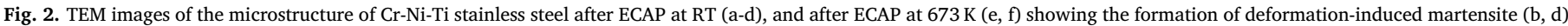
and deformation twins (c, f) with corresponding SAED patterns.
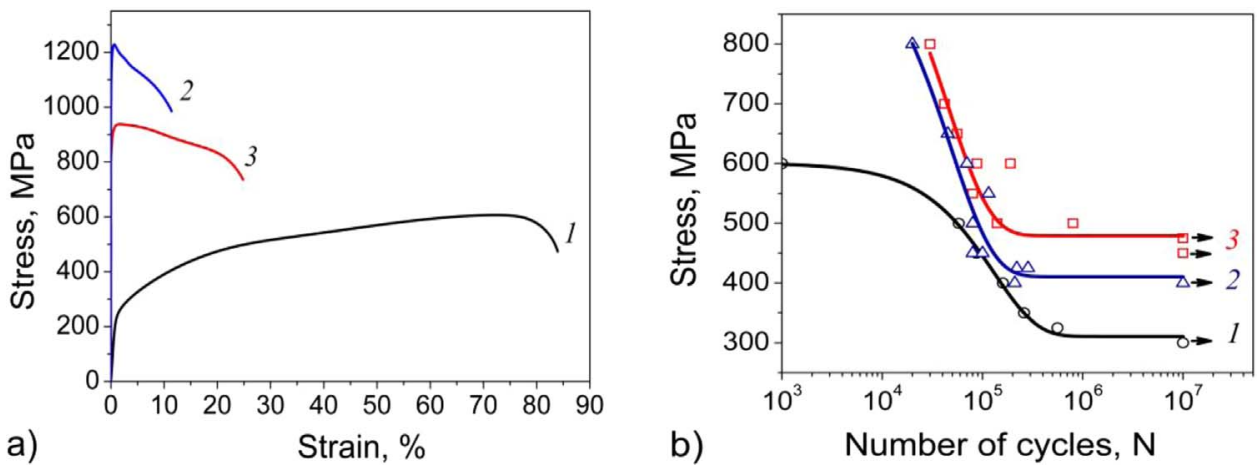

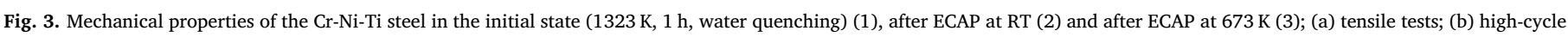
fatigue tests. 
Table 3

Mechanical properties of $\mathrm{Cr}-\mathrm{Ni}$-Ti stainless steel.

\begin{tabular}{llllll}
\hline Processing & $\sigma_{\mathrm{y}},[\mathrm{MPa}]$ & $\sigma_{\mathrm{UTS}},[\mathrm{MPa}]$ & $\varepsilon,[\%]$ & $\sigma_{\mathrm{f}},[\mathrm{MPa}]$ & $\sigma_{\mathrm{f}} / \sigma_{\mathrm{UTS}}$ \\
\hline Quenching & 200 & 607 & 84 & 275 & 0.45 \\
ECAP at RT & 1173 & 1228 & 11 & 375 & 0.31 \\
ECAP at 673 K & 870 & 937 & 25 & 475 & 0.51 \\
\hline
\end{tabular}

* $\sigma_{\mathrm{y}}$-yield strength; $\sigma_{\mathrm{UTS}}$-ultimate tensile strength; $\varepsilon$-total elongation; $\sigma_{\mathrm{f}}$-fatigue limit.

boundaries and half of them belong to special $\Sigma 3$ boundaries. Therefore, the Cr-Ni-Ti steel structure in the initial state is a typical coarsegrained $(20-30 \mu \mathrm{m})$ austenitic structure with numerous annealing twins as shown in Fig. 1b, c and Table 2.

The XRD analysis of the initial microstructure revealed about $7.6 \%$ of bcc-phase, which is commonly identified as remaining $\delta$-ferrite (Table 2) In steels of similar composition, the fraction of $\delta$-ferrite below $10 \%$ is frequently observed after quenching. EBSD revealed $23 \%$ of bcc - phase in the initial microstructure, which is obviously overestimated.
3.2. Microstructural evolution during ECAP at room temperatures and at $673 \mathrm{~K}$

The EBSD analysis revealed the grain structure with a fraction of high-angle grain boundaries of $59 \%$ and an average grain size of $410 \mathrm{~nm}$ after ECAP at room temperature. The average size of structural elements of $360 \mathrm{~nm}$ was obtained, taking into account low-angle subboundaries. EBSD revealed that the microstructure contains about 3\% of twin boundaries. In comparison with the initial state, ECAP at RT leads to a considerable reduction of the twin fraction and to an increase in the fraction of low-angle grain boundaries (Table 2). These changes are associated with the formation of a subgrain structure inside the initial grains during ECAP. It is necessary to note that the twins with a thickness of less than $50 \mathrm{~nm}$ are hard to define by EBSD [11].

At the same time, it was revealed by the TEM analysis that the subgrain/grain structure with a size of structural elements of 100-250 nm was formed during ECAP at RT (Fig. 2a). The size of structural elements revealed by EBSD analysis is somewhat larger than that obtained by TEM analysis because the fine structural elements with
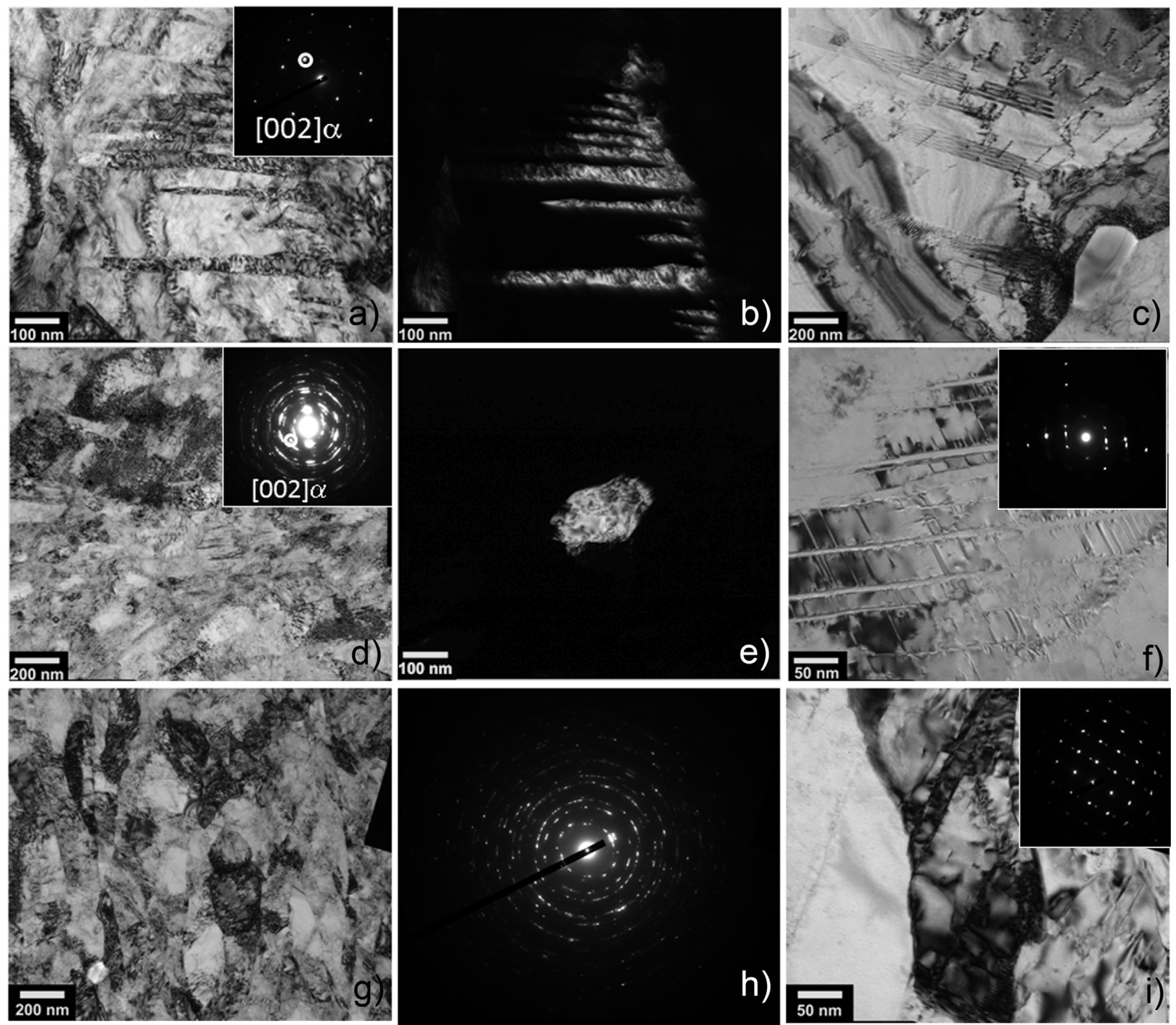

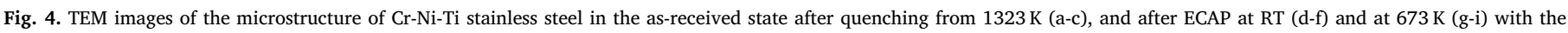
subsequent fatigue tests (after $\mathrm{N}=10^{7}$ cycles at $\sigma_{\max }=300 \mathrm{MPa}$ in the initial state, at $\sigma_{\max }=400 \mathrm{MPa}$ after ECAP at RT and at $\sigma_{\max }=450 \mathrm{MPa}$ after ECAP at $673 \mathrm{~K}$ ). 

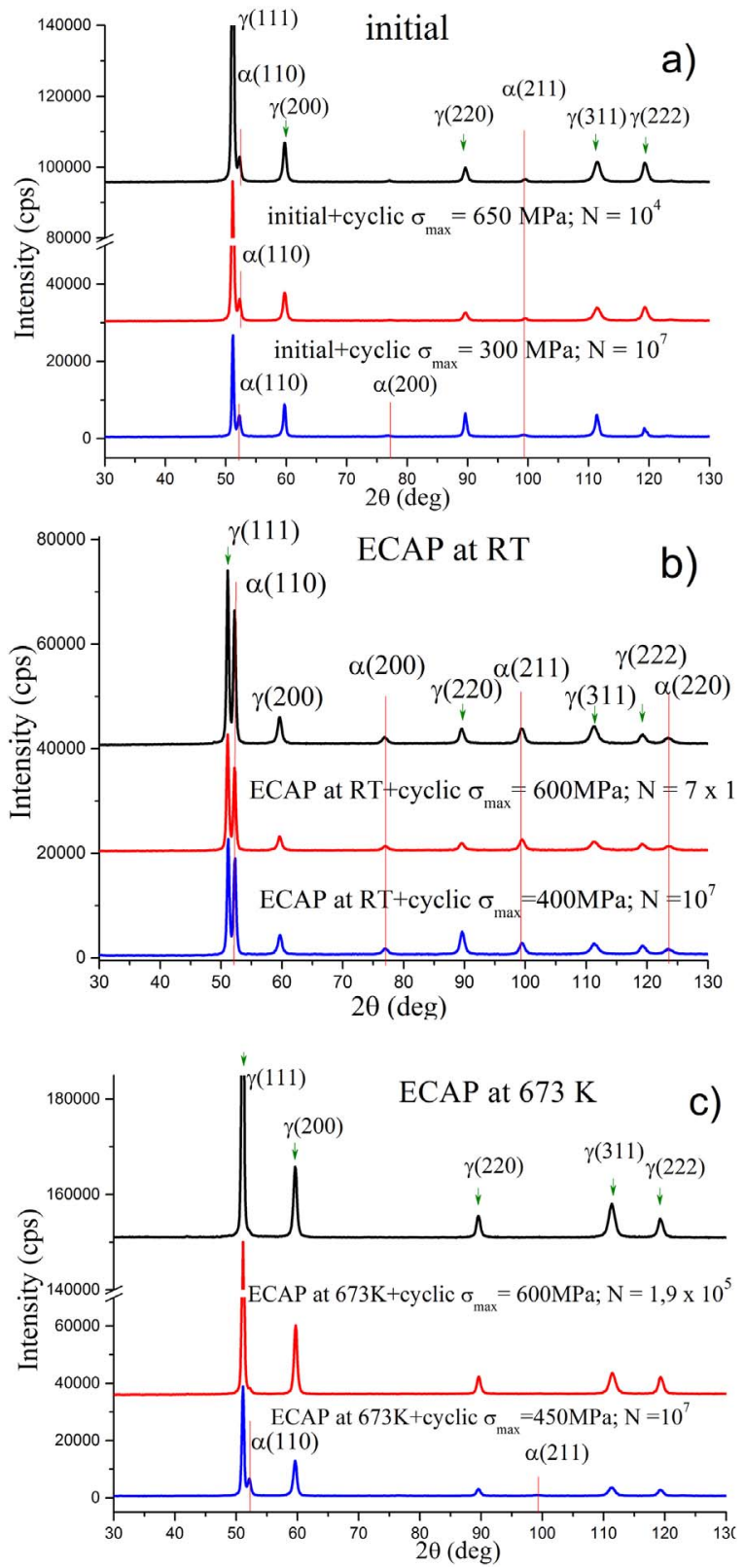

Fig. 5. X-ray diffractions of the Cr-Ni-Ti steel before and after cyclic deformation in the initial state (1323 K, $1 \mathrm{~h}$, water quenching) (a), after ECAP at RT (b) and after ECAP at $673 \mathrm{~K}(\mathrm{c})$.

a size below $50 \mathrm{~nm}$ and low-angle subboundaries with a misorientation smaller than $2^{\circ}$ are not recognized by EBSD.

The martensitic transformation takes place during ECAP at room temperature conducted on austenitic steel. The XRD analysis suggests that there is no complete transformation of $\gamma$-phase into $\alpha$-martensite during ECAP, i.e., including $\delta$-ferrite the amount of bcc-phase is about $38 \%$. It is important to note that EBSD shows only $36 \%$ of martensite. The TEM analysis revealed the deformation martensite (Fig. 2b, d) and the deformation twins (Fig. 2c). Also, TEM analysis shows the thickness of the twins of 5-10 nm, meanwhile the EBSD shows more than $50 \mathrm{~nm}$. Therefore, the EBSD analysis does not give the exact value of the twin density.

The formation of subgrain/grain structure with an average size of structural elements of $500 \mathrm{~nm}$ was revealed by EBSD analysis after ECAP at $673 \mathrm{~K}$ (Table 2). The subgrain structure is partially aligned. The subgrain size comprises about a half of the average grain size, which is $\sim 940 \mathrm{~nm}$ and the fraction of high-angle grain boundaries is nearly 54\%. It looks like the fraction of high-angle grain boundaries decreases at the expense of the formation of a subgrain structure inside the initial grains much similar to ECAP at RT. The EBSD analysis reveals the fraction of twins of about $1 \%$, while the TEM analysis shows very thin deformation twins (Fig. 2f). Both TEM and XRD analyses prove that fully austenitic microstructure with a size of structural elements of $100-400 \mathrm{~nm}$ evolve during equal channel angular pressing at $673 \mathrm{~K}$ (Fig. 2e).

Thus, the EBSD analysis shows that both ECAP at RT and at $673 \mathrm{~K}$ lead to the formation of submicron subgrain/grain structure with the fraction of high-angle grain boundaries of 59\% and 54\%, respectively. The size of subgrains and especially grains after ECAP at RT is less than that after ECAP at $673 \mathrm{~K}$. The size of structural elements determined by the TEM analysis is less than that determined by EBSD. During ECAP at RT, about $40 \%$ of martensite is formed in the austenitic structure. After ECAP at $673 \mathrm{~K}$ the steel is completely in the austenitic state as this temperature is higher than that for deformation martensite.

\subsection{Improve mechanical properties under static and cyclic loading}

The tensile stress-strain curves are shown in Fig. 3a. The initial steel sample is characterized by the yield strength of $200 \mathrm{MPa}$, ultimate tensile strength of $607 \mathrm{MPa}$ and total elongation of $84 \%$. After ECAP at RT, the yield strength of $1173 \mathrm{MPa}$, ultimate tensile strength of $1228 \mathrm{MPa}$ and total elongation decreased to $11 \%$. Comparing to room temperature, ECAP at $673 \mathrm{~K}$ leads to slightly lower strength values of the yield strength of $870 \mathrm{MPa}$ and ultimate tensile strength of $937 \mathrm{MPa}$, but to a higher ductility, i.e., total elongation of $25 \%$ (Fig. 3a, Table 3).

The S-N curves of the austenitic steel under cyclic stress loading are shown in Fig. 3b. It was revealed that after ECAP at room temperature the strength is higher than in the initial quenched state, and the value of the fatigue limit is also increased and reaches $375 \mathrm{MPa}$, which is higher than that in the quenched state by $100 \mathrm{MPa}$. After ECAP at $673 \mathrm{~K}$ the fatigue limit increases up to $475 \mathrm{MPa}$. It should be noted that the samples after ECAP at $673 \mathrm{~K}$ demonstrate the best results for the ratio of the endurance limit to the ultimate tensile strength $\left(\sigma_{\mathrm{f}} / \sigma_{\mathrm{UTS}}\right)$, indicating the best working capacity of the material under cyclic loading (Table 3).

The better fatigue characteristics of the samples after ECAP at $673 \mathrm{~K}$ than those of the samples subjected to ECAP at RT, can be explained by the fully austenitic microstructure of the stainless steel after ECAP at $673 \mathrm{~K}$. Therefore, an additional deformation strengthening in the highcycle fatigue can be attributed to the rearrangement of the dislocation substructure and an additional increase in the dislocation density, as well as the local formation of the strain-induced martensite.

Thus, the improvement of the fatigue strength is provided by not only the initial microstructure, but also by the structural and phase transformations taking place during cyclic deformation.

\subsection{Microstructural evolution during high-cycle fatigue tests}

An EBSD analysis was conducted after cyclic testing at $\sigma_{\max }=$ $600 \mathrm{MPa}$ and $\mathrm{N}=7 \times 10^{4}$ cycles (for ECAP at RT) and $\mathrm{N}=1.9 \times 10^{5}$ cycles (for ECAP at $673 \mathrm{~K}$ ). The analysis shows that the fraction of twins for both ECAP temperatures is very small, as the EBSD method does not determine the fine deformation twins. This fraction of twins apparently does not change during cyclic loading. However, the EBSD analysis shows an increase in the volume fraction of martensite by 1.4 times (from $36 \%$ to $50 \%$ ) and the fraction of high-angle grain boundaries by 1.1 times (from $59 \%$ to $65 \%$ ) during cyclic tests of the samples after ECAP at RT (Table 2). The cyclic deformation does not change the average size of structural elements and grains despite an increase in the fraction of high-angle grain boundaries (Table 2). This may be explained by the small difference in grain and subgrain sizes.

According to the EBSD analysis, the cyclic testing after ECAP at $673 \mathrm{~K}$ results in an increase in the fraction of high-angle grain 
Table 4

Crystallite size, microstrain, and fraction of martensite of the $\mathrm{Cr}-\mathrm{Ni}$-Ti steel determined by X-ray line profile analysis.

\begin{tabular}{|c|c|c|c|c|c|}
\hline Processing & & Phase & Crystallite size, $[\mathrm{nm}]$ & $\varepsilon,[\%]$ & Fraction, [vol.\%] \\
\hline \multirow[t]{6}{*}{ Quenching } & Without cyclic testing & $\alpha-\mathrm{Fe}$ & - & & 7. $6 \pm 0.1$ \\
\hline & & $\gamma-\mathrm{Fe}$ & - & $0.106 \pm 0.009$ & $92.4 \pm 0.1$ \\
\hline & Cyclic testing $\left(\sigma^{* \max }=600 \mathrm{MPa} ; \mathrm{N}^{\mathrm{a}}=10^{3)}\right.$ & $\alpha-\mathrm{Fe}$ & - & - & 9. $6 \pm 0.1$ \\
\hline & & $\gamma-\mathrm{Fe}$ & - & $0.112 \pm 0.010$ & $90.4 \pm 0.1$ \\
\hline & Cyclic testing $\left(\sigma_{\max }^{*}=300 \mathrm{MPa} ; \mathrm{N}^{\mathrm{a}}=10^{7}\right)$ & $\alpha-\mathrm{Fe}$ & - & - & $10.8 \pm 0.1$ \\
\hline & & $\gamma-\mathrm{Fe}$ & - & - & $89.2 \pm 0.1$ \\
\hline \multirow[t]{6}{*}{ ECAP at RT } & Without cyclic testing & $\alpha-\mathrm{Fe}$ & $122.8 \pm 25.0$ & $0.277 \pm 0.027$ & $38.3 \pm 0.1$ \\
\hline & & $\gamma-\mathrm{Fe}$ & $66.7 \pm 10.0$ & $0.205 \pm 0.020$ & $61.7 \pm 0.1$ \\
\hline & Cyclic testing $\left(\sigma_{\max }=600 \mathrm{MPa} ; \mathrm{N}=7 \times 10^{4}\right)$ & $\alpha-\mathrm{Fe}$ & $76.1 \pm 25.0$ & $0.301 \pm 0.029$ & $43.8 \pm 0.2$ \\
\hline & & $\gamma-\mathrm{Fe}$ & $86.1 \pm 15.0$ & $0.228 \pm 0.023$ & $56.2 \pm 0.2$ \\
\hline & Cyclic testing $\left(\sigma_{\max }=400 \mathrm{MPa} ; \mathrm{N}=10^{7}\right)$ & $\alpha-\mathrm{Fe}$ & $90.2 \pm 20.0$ & $0.296 \pm 0.029$ & $39.8 \pm 0.1$ \\
\hline & & $\gamma-\mathrm{Fe}$ & $54.0 \pm 25.0$ & $0.178 \pm 0.047$ & $60.2 \pm 0.1$ \\
\hline \multirow[t]{5}{*}{ ECAP at $673 \mathrm{~K}$} & Without cyclic testing & $\gamma-\mathrm{Fe}$ & $108.1 \pm 15.0$ & $0.122 \pm 0.033$ & $100 \pm 0.0$ \\
\hline & Cyclic testing $\left(\sigma_{\max }=600 \mathrm{MPa} ; \mathrm{N}=1,9 \times 10^{5}\right)$ & $\alpha-\mathrm{Fe}$ & - & - & $3.3 \pm 0.1$ \\
\hline & & $\gamma-\mathrm{Fe}$ & $108.7 \pm 20.0$ & $0.145 \pm 0.015$ & $96.7 \pm 0.1$ \\
\hline & Cyclic testing $\left(\sigma_{\max }=450 \mathrm{MPa} ; \mathrm{N}^{\mathrm{a}}=10^{7}\right)$ & $\alpha-\mathrm{Fe}$ & - & - & $10.3 \pm 0.1$ \\
\hline & & $\gamma-\mathrm{Fe}$ & $76.3 \pm 32.0$ & $0.133 \pm 0.035$ & $89.7 \pm 0.1$ \\
\hline
\end{tabular}

$\mathrm{N}$ - number of cycles to failure.

${ }^{a} \sigma_{\max }$, -maximum stress.

boundaries by 1.3 times (from $54 \%$ to $70 \%$ ) appearance of martensite by $13.8 \%$. The average size of structural elements does not change and the mean grain size decreases from 940 to $640 \mathrm{~nm}$ (Table 2). A possible explanation may be that after ECAP at $673 \mathrm{~K}$ the size of subgrains is two times smaller than that of grains. Obtained increase in the percentage of high-angle grain boundaries by $16 \%$ during cyclic deformation can be caused by an increase in the misorientation of a portion of subboundaries above $15^{\circ}$. That is to say that the subgrains become grains by continuous dynamic recrystallization, and sizes of both grains and subgrains should be almost the same. Such microstructure evolution leads to a decrease in the average grain size during cyclic loading.

The TEM analysis reveals the partial martensitic transformation and the deformation twinning during cyclic deformation of the initial steel samples and those after both ECAP temperatures (Fig. 4). The formation of deformation-induced martensite (Fig. 4a, b, d, e), deformation twins (Fig. 4f, i) with corresponding SAED patterns and strain-induced stacking faults (Fig. 4c) can be clearly seen. The SAED pattern in Fig. 4a was obtained from the area of $300 \mathrm{~nm}$, those in (Fig. 4d and h) $1400 \mathrm{~nm}$, and those in (Fig. $4 \mathrm{f}$ and i) $-125 \mathrm{~nm}$. The dark field images in Fig. $4 \mathrm{~b}$ and e were obtained from the scattered beams indicated in SAED patterns in Fig. 4a and d, respectively. The size of selected areas in SAED patterns is limited by the diameter of the circular apertures. Generally, the size of the aperture should roughly correspond to the size of the studied structural element to clearly show the features inherent in this element. The largest aperture was used for the deformation-induced martensite in order to facilitate and simplify the finding and definition of the martensite.

The XRD analysis also reveals the martensitic transformation during the cyclic deformation (Fig. 5). In the initial state, the cyclic testing at $\sigma_{\max }=650 \mathrm{MPa}$ and $\mathrm{N}=10^{4}$ cycles leads to the additional formation of $2 \%$ martensite, and at $\sigma_{\max }=300 \mathrm{MPa}$ and $\mathrm{N}=10^{7}$ cycles - to $3.2 \%$ martensite. After $\mathrm{N}=7 \times 10^{4}$ cycles at $\sigma_{\max }=600 \mathrm{MPa}$ in the samples after ECAP at RT, the amount of martensite is increased by 1.14 times (from $38.3 \%$ to $43.8 \%$ ), but after $\sigma_{\max }=400 \mathrm{MPa}$ and $\mathrm{N}=10^{7}$ cycles it is only appeared in addition by $1.5 \%$. In the completely austenitic UFG matrix after ECAP at $673 \mathrm{~K}, 3.3 \%$ of martensite appears after $\mathrm{N}=$ $1.9 \times 10^{5}$ cycles at $\sigma_{\max }=600 \mathrm{MPa}$ and $10.3 \%$ of martensite after $\mathrm{N}=$ $10^{7}$ cycles at $\sigma_{\max }=450 \mathrm{MPa}$ (Table 4, Fig. 5). It should be noted that EBSD and XRD analyses of the quantity of martensite during cyclic deformation do not always coincide. According to the literature, XRD analysis more accurately determines the amount of martensite in austenite [11]. The data obtained do not allow revealing the regularities of the martensitic transformation versus the stress amplitude and the number of cycles during the fatigue tests of the UFG austenitic steel. It can only be stated that a partial martensitic transformation takes place during the cyclic loading of the UFG Cr-Ni-Ti steels and that it may result in increasing the fatigue limit.

The mean crystallite size, mean value of microstrain of the steel after ECAP and subsequent cyclic tests were determined by the XRD line profile analysis of (111) and (222) lines (Table 4). The crystallite size measured by the X-ray line profile analysis is lower than the grain size obtained by the EBSD analysis and that revealed by TEM (Tables 2 and 4). This is typical feature of materials after SPD. The findings are in agreement with previous results [34-36] implying that the crystallite size corresponds to the subgrain/cell size.

ECAP at RT and $673 \mathrm{~K}$ leads to a significant decrease in the crystallite size in the $\gamma$-phase compared to the initial austenite grain size. The crystallite size after ECAP at $673 \mathrm{~K}$ is slightly larger than that after ECAP at RT (Table 4). Cyclic loading under the present conditions has almost no effect on the crystallite size in the $\gamma$-phase irrespective of the previous ECAP temperature. The variations of the crystallite sizes are within the error of measurement. After ECAP at RT the crystallite size in the $\alpha$-phase also does not depend on the subsequent cyclic deformation. The crystallites in the $\alpha$-phase are larger than in the $\gamma$-phase after ECAP at RT.

The microstrains determined in the $\gamma$-phase also do not change during cyclic loading of the initial steel samples and those after ECAP at both temperatures (Table 4). The average microstrains after ECAP at both temperatures are larger than those in the initial state, and the microstrains after ECAP at $293 \mathrm{~K}$ are larger than those at $673 \mathrm{~K}$. The microstrains in the $\alpha$-phase after ECAP at $293 \mathrm{~K}$ are larger than in the $\gamma$ phase and they also do not change during cyclic loading.

\section{Conclusions}

The mechanical properties of a metastable austenitic stainless steels processed by equal channel angular pressing (ECAP) were investigated under static and cyclic loading conditions. The strength characteristics and microstructural changes were analyzed. Based on this analysis, the following conclusions can be drawn:

(1) ECAP at room temperature (RT) and at $673 \mathrm{~K}$ lead to the formation of submicron subgrain/grain structure with the fraction of highangle grain boundaries of $59 \%$ and $54 \%$, respectively. The sizes of subgrains of $360 \mathrm{~nm}$ and, especially, grains of $430 \mathrm{~nm}$ after ECAP at RT are smaller than those of $500 \mathrm{~nm}$ and $940 \mathrm{~nm}$, respectively, after ECAP at $673 \mathrm{~K}$. During ECAP at RT about $40 \%$ of martensite is formed in the austenitic structure. After ECAP at $673 \mathrm{~K}$ the steel is 
completely in the austenitic state as this temperature is higher than that for martensite formation by deformation.

(2) The mechanical properties of the metastable austenitic stainless steel is significantly improved by ECAP. The yield strength is increased by a factor of 3.8 or 5.2 , the ultimate tensile strength by a factor of 1.5 or 2.2 and the fatigue limit by a factor of 1.4 or 1.7 by ECAP at $673 \mathrm{~K}$ or at room temperature, respectively.

(3) The fatigue strength is remarkably improved due to the grain refinement and deformation twinning resulted from ECAP, as well as owing to intensive deformation twinning, partial martensitic transformation and increasing the fraction of high-angle grain boundaries during high-cycle fatigue testing. The steel processed by ECAP at $673 \mathrm{~K}$ is characterized by superior fatigue limit as compared to that after ECAP at room temperature because of grain refinement, together with, an increase in the fraction of high-angle grain boundaries, and the partial martensitic transformation of the austenitic ultrafine-grained matrix during cyclic deformation.

\section{Acknowledgements}

The work was supported by the Russian Foundation for Basic Research (grant 16-08-00365-a) and by the Increased Competitiveness Program of NUST"MISiS". EBSD observations was carried out within the governmental task 007-00129-18-00.

\section{References}

[1] I.I. Kositsyna, V.V. Sagaradze, V.I. Kopylov, Formation of high-strength and highplastic state in metastable austenitic steels by the method of equal-channel angular pressing, Fiz. Met. Metalloved. 88 (5) (1999) 493-498.

[2] S.V. Dobatkin, R.Z. Valiev, L.M. Kaputkina, N.A. Krasilnikov, O.V. Sukhostavskaya, V.S. Komlev, Recrystallization of Steels with Submicrocrystalline Structure, in: Proceedings of the Fourth International Conference on Recrystallization and Related Phenomena, (REX'99), Tsukuba City, Japan, 1999, T. Sakai, H.G. Suzuki (ed.) JIM 13, pp. 907-912, 1999.

[3] S.S.M. Tavares, D. Gunderov, V. Stolayrov, J.M. Neto, Phase transformation induced by severe plastic deformation in the AISI 304L stainless steel, Mater. Sci. Eng. A 358 (2003) 32-36, http://dx doi.org/10.1016/S0921-5093(03)00263-6.

[4] S. Scheriau, Z. Zhang, S. Kleber, R. Pippan, Deformation mechanisms of a modified 316L austenitic steel subjected to high pressure torsion, Mater. Sci. Eng. A 528 (2011) 2776-2786, http://dx.doi.org/10.1016/j.msea.2010.12.023.

[5] S.V. Dobatkin, O.V. Rybal'chenko, G.I. Raab, Structure formation, phase transformations and properties in $\mathrm{Cr}-\mathrm{Ni}$ austenitic steel after equal-channel angular pressing and heating, Mater. Sci. Eng. A 463 (2007) 41-45, http://dx.doi.org/10. 1016/j.msea.2006.07.156.

[6] O.V. Rybalchenko, S.V. Dobatkin, L.M. Kaputkina, G.I. Raab, N.A. Krasilnikov, Strength of ultra-grained corrosion-resistant steels after severe plastic deformation, Mater. Sci. Eng. A 387-389 (2004) 244-248, http://dx.doi.org/10.1016/j.msea. 2004.03.097.

[7] J. Talonen, H. Hanninen, Formation of shear bands and strain-induced martensite during plastic deformation of metastable austenitic stainless steels, Acta Mater. 55 (2007) 6108-6118, http://dx.doi.org/10.1016/j.actamat.2007.07.015.

[8] H. Ueno, K. Kakihata, Y. Kaneko, S. Hashimoto, A. Vinogradov, Nanostructurization assisted by twinning during equal channel angular pressing of metastable 316L stainless steel, J. Mater. Sci. 46 (12) (2011) 4276-4283, http://dx.doi.org/10. 1007/s10853-011-5303-4.

[9] H. Ueno, K. Kakihata, Y. Kaneko, S. Hashimoto, A. Vinogradov, Enhanced fatigue properties of nanostructured austenitic SUS 316L stainless steel, Acta Mater. 59 (2011) 7060-7069, http://dx doi.org/10.1016/j.actamat 2011.07.061.

[10] V.F. Terent'ev, S.V. Dobatkin, D.V. Prosvirnin, I.O. Bannykh, O.V. Rybal'chenko, G.I. Raab, Fatigue strength of austenitic Kh18N10T steel after equal-channel angular pressing, Deform. i Razrushenie Mater. 10 (2008) 30-38 (In Russian).

[11] S.V. Dobatkin, V.F. Terent'ev, W. Skrotzki, O.V. Rybalchenko, M.N. Pankova, D.V. Prosvirnin, E.V. Zolotarev, Structure and fatigue properties of 08Kh18N10T steel after equal-channel angular pressing and heating, Russ. Metall. (Met.) 11 (2012) 954-962, http://dx.doi.org/10.1134/S0036029512110043.

[12] L. Kunz, P. Lukas, M. Svoboda, Fatigue strength, microstructural stability and strain localization in ultrafine-grained copper, Mater. Sci. Eng. A 424 (2006) 97-104 http://dx.doi.org/10.1016/j.msea.2006.02.029.

[13] I.P. Semenova, R.Z. Valiev, E.B. Yakushina, G.H. Salimgareeva, T.C. Lowe, Strength and fatigue properties enhancement in ultrafine-grained Ti produced by severe plastic deformation, J. Mater. Sci. 43 (2008) 7354-7359, http://dx.doi.org/10 1007/s10853-008-2984-4.
[14] J. May, D. Amberger, M. Dinkel, H.W. Höppel, M. Göken, Monotonic and cyclic deformation behaviour of ultrafine-grained aluminium, Mater. Sci. Eng. A 483-484 (2008) 481-484, http://dx.doi.org/10.1016/j.msea.2006.12.177.

[15] H. Mughrabi, H.W. Huppel, M. Kautz, Fatigue and microstructure of ultrafinegrained metals produced by severe plastic deformation, Scr. Mater. 51 (2004) 807-812, http://dx.doi.org/10.1016/j.scriptamat.2004.05.012.

[16] H.W. Höppel, M. Kautz, C. Xu, M. Murashkin, T.G. Langdon, R.Z. Valiev, H. Mughrabi, An overview: fatigue behaviour of ultrafine-grained metals and alloys, Int. J. Fatigue 28 (2006) 1001-101010, http://dx.doi.org/10.1016/j.ijfatigue.2005. 08.014 .

[17] S. Cheng, J. Xie, A.D. Stoica, X.-L. Wang, J.A. Horton, D.W. Brown, H. Choo, P.K. Liaw, Cyclic deformation of nanocrystalline and ultrafine-grained nickel, Acta Mater. 57 (2009) 1272-1280, http://dx.doi.org/10.1016/j.actamat.2008.11.011.

[18] I. Altenberger, B. Scholtes, U. Martin, H. Oettel, Cyclic deformation and near surface microstructures of shot peened or deep rolled austenitic stainless steel AISI 304, Mater. Sci. Eng. A. 264 (1999) 1-16, http://dx.doi.org/10.1016/S09215093(98)01121-6.

[19] Y. Furuya, S. Matsuoka, S. Shimakura, T. Hanamura, S. Torizuka, Fatigue strength of ultrafine ferrite-cementite steels and effects of strengthening mechanisms, Metall. Mater. Trans. A 38 (2007) 2984-2991, http://dx.doi.org/10.1007/s11661-0079355-7.

[20] T. Hanlon, Y.N. Kwon, S. Suresh, Grain size effects on the fatigue response of nanocrystalline metals, Scr. Mater. 49 (2003) 675-680, http://dx.doi.org/10.1016/ S1359-6462(03)00393-2.

[21] A.S. Hamada, L.P. Karjalainen, High-cycle fatigue behavior of ultrafine-grained austenitic stainless and TWIP steels, Mater. Sci. Eng. A 527 (2010) 5715-5722, http://dx.doi.org/10.1016/j.msea.2010.05.035.

[22] K.H. Lo, C.H. Shek, J.K.L. Lai, Recent Developments in Stainless Steels, Mater. Sci. Eng. R 65 (2009) 39-104, http://dx.doi.org/10.1016/j.mser.2009.03.001.

[23] D.-Y. Ryoo, N. Kang, C.-Y. Kang, Effect of Ni content on the tensile properties and strain-induced martensite transformation for 304 stainless steel, Mater. Sci. Eng. A 528 (2011) 2277-2281, http://dx.doi.org/10.1016/j.msea.2010.12.022.

[24] C. Lei, X. Li, X. Deng, Z. Wang, G. Wang, Deformation mechanism and ductile fracture behavior in high strength high ductility nano/ultrafine grained $\mathrm{Fe}-17 \mathrm{Cr}$ 6Ni austenitic steel, Mater. Sci. Eng. A 709 (2018) 72-81, http://dx.doi.org/10. 1016/j.msea.2017.10.043.

[25] G.S. Sun, L.X. Du, J. Hu, R.D.K. Misra, Microstructural evolution and recrystallization behavior of cold rolled austenitic stainless steel with dual phase microstructure during isothermal annealing, Mater. Sci. Eng. A 709 (2018) 254, http://dx.doi.org/10.1016/j.msea.2017.10.054.

[26] I. Nikulin, T. Sawaguchi, K. Tsuzaki, Effect of alloying composition on low-cycle fatigue properties and microstructure of Fe-30Mn- $(6-x) \mathrm{Si}-\mathrm{xAl}$ TRIP/TWIP alloys, Mater. Sci. Eng. A 587 (2013) 192-200, http://dx.doi.org/10.1016/j.msea.2013. 08.061.

[27] H. Jafarian, Characteristics of nano/ultrafine-grained austenitic TRIP steel fabricated by accumulative roll bonding and subsequent annealing, Mater. Charact. 114 (2016) 88-96, http://dx.doi.org/10.1016/j.matchar.2016.02.012.

[28] S. Tirekar, H.R. Jafarian, A.R. Eivani, Towards engineering of mechanical properties Through stabilization of austenite in ultrafine grained martensite-austenite dual phase steel processed by accumulative roll bonding, Mater. Sci. Eng. A 684 (2017) 120-126, http://dx.doi.org/10.1016/j.msea.2016.12.039.

[29] H.R. Jafarian, M.F. Tarazkouhi, Significant enhancement of tensile properties Through combination of severe plastic deformation and reverse transformation in an ultrafine/nano grain lath martensitic steel, Mater. Sci. Eng. A 686 (2017) 113-120, http://dx.doi.org/10.1016/j.msea.2017.01.034.

[30] H.R. Jafarian, S.H. Mousavi Anijdan, A.R. Eivani, N. Park, A comprehensive study of microstructure development and its corresponding tensile properties in nano/ ultrafine-grained metastable austenitic steel during accumulative roll bonding (ARB), Mater. Sci. Eng. A 703 (2017) 196-204, http://dx.doi.org/10.1016/j.msea. 2017.07.050.

[31] R.Z. Valiev, T.G. Langdon, Principles of equal-channel angular pressing as a processing tool for grain refinement, Prog. Sci. 51 (7) (2006) 881-981, http://dx.doi org/10.1016/j.pmatsci.2006.02.003.

[32] Y. Iwahashi, Z. Horita, M. Nemoto, T.G. Langdon, An investigation of microstructural evolution During equal-channel angular pressing, Acta Mater. 45 (1997) 4733-4741, http://dx.doi.org/10.1016/S1359-6454(97)00100-6.

[33] Y. Iwahashi, J. Wang, Z. Horita, M. Nemoto, T.G. Langdon, Principle of equalchannel angular pressing for the processing of ultra-fine grained materials, Scr. Mater. 35 (2) (1996) 143-146, http://dx.doi.org/10.1016/1359-6462(96)00107-8.

[34] J. Gubicza, T. Ungár, Characterization of defect structures in nanocrystalline materials by X-ray line profile analysis, Z. Krist. 222 (2007) 567-579, http://dx.doi. org/10.1524/zkri.2007.222.11.567.

[35] T. Ungár, J. Gubicza, G. Rib’arik, A. Borb’ely, Crystallite size distribution and dislocation structure determined by diffraction profile analysis: principles and practical application to cubic and hexagonal crystals, J. Appl. Cryst. 34 (2001) 298-310.

[36] Y.D. Yagodkin, S.V. Dobatkin, Application of electron microscopy and x-ray structural analysis for the determination of sizes of structural elements in nanocrystalline materials (review), Inorg. Mater. 44 (2008) 1520-1530, http://dx.doi.org/10. 1134/S0020168508140070. 